\title{
$\widehat{A}$ Madridge
}

madridge Journal of Women's Health and Emancipation

interconnecting Scientific World

Research Article

Open Access

\section{Female Sexual Dysfunction among Contraceptive User in Malaysia}

\author{
Adibah Hanim Ismail ${ }^{1 \star}$, Md S Hafizah ${ }^{2}$ and Ching Siew Mooi ${ }^{1}$ \\ ${ }^{l}$ Family Medicine Department, Faculty of Medicine E Health Sciences, Universiti Putra Malaysia, 43400 Serdang, Selangor, Malaysia \\ ${ }^{2}$ Ministry of Health, Malaysia
}

Article Info

*Corresponding author:
Adibah Hanim Ismail
Family Medicine Department
Faculty of Medicine and Health Sciences
Universiti Putra Malaysia
43400 Serdang
Selangor, Malaysia
E-mail: nasuha9999@yahoo.com

Received: September 27, 2017

Accepted: October 13, 2017

Published: October 19, 2017

Citation: Ismail AH, Hafizah MS, Ching SM. Female Sexual Dysfunction among Contraceptive User in Malaysia. Madridge J Womens Health Emancipation. 2017; 1(1): 36-40. doi: $10.18689 / \mathrm{mjwh}-1000108$

Copyright: ( $\odot 2017$ The Author(s). This work is licensed under a Creative Commons Attribution 4.0 International License, which permits unrestricted use, distribution, and reproduction in any medium, provided the original work is properly cited.

Published by Madridge Publishers

\begin{abstract}
Background: Women in reproductive age are at risk of getting female sexual dysfunction (FSD). Contraception has been recognized as one of the causes of FSD. This study aims to determine the prevalence of FSD and types of FSD among contraceptive user.
\end{abstract}

Methods: This is a cross-sectional study involving 262 women who were on contraception in eleven primary care clinics in Malaysia. Malay version of Female Sexual Function Index (MVFSFI) was used in this study.

Results: The prevalence of FSD among contraceptive user in Malaysia was 9.5\% ( $n=25)$. The highest types of female sexual dysfunction in this study were sexual dissatisfaction $(29.8 \%, n=78)$ and sexual desire disorder $(29.4 \%, n=77)$. Majority of the participants were Malay (83.6\%). Of twenty-five women with FSD, one-third of them was Indian ethnic. Most of the women (11.2\%) with FSD had received education up to secondary school and non- employed (11.6\%). Twenty-two (9.9\%) women with FSD were practising hormonal contraception and most of them were dissatisfied with their marital relationship $(35.7 \%, n=5)$.

Conclusions: The result indicates that one in ten contraceptive users had FSD. The highest percentage of female sexual dysfunction domain was sexual dissatisfaction and sexual desire disorder. Hormonal contraception was the most common method used among women with FSD. Further research is needed to determine the associated factor of female sexual dysfunction among women using contraception.

Keywords: Prevalence; Sexual dysfunction; Contraception

\section{Introduction}

Female sexual dysfunction (FSD) is defined as "disturbance in sexual desire and psycho physiological changes that characterize the sexual response cycle causing marked distress or interpersonal difficulty" based on DSM IV criteria. The recent DSM V criteria published in 2013 describe FSD as the same as DSM IV. The main differences are in the diagnostic subcategories whereby it combines sexual desire disorder and arousal disorder into one main category that is female sexual interest/arousal disorder [1].

Despite being an unrevealing issue in sexual health, female sexual dysfunction is not uncommon worldwide. The prevalence of FSD is high and varies depending on the population that has been studied. In the western countries, there was a wide range of reported prevalence of FSD from $11 \%$ to $65 \%$ [2, 3]. Similar to Malaysia, the prevalence of FSD among contraceptive user also varies from $5.5 \%$ to $29.4 \%$ in the different study population $[4,5]$. 
The report of the International Consensus Development Conference of Female Sexual Dysfunction in Boston classified FSD into six disorders that are sexual desire, arousal, lubrication, satisfaction, orgasm and pain disorder [6]. This classification of FSD became the basis of development of Female Sexual Function Index (FSFI) to assessed sexual dysfunction in female [7]. Since then, this tool had been used worldwide including in Malaysia whereby a Malay version of FSFI had been translated and validated for local used [8]. The frequency of FSD domain also varies. In Malaysia study done in 2007 found that sexual pain disorder was the commonest disorder (67.8\%) followed by sexual arousal disorder (60.9\%) [4]. But in 2010 [9], the sexual desire was the highest reported prevalence (39.3\%) followed by sexual arousal disorder $(25.8 \%)$ in 163 sexually active women regardless their contraceptive method.

A hormonal contraception particularly oral contraceptive pill (OCP) has been shown to cause FSD. This could be due dysregulation of sex hormone, decrease in vaginal lubrication and vestibulodynia $[10,11,12]$. A few studies reported that women who were practicing any types of contraception had a significantly lower mean of FSFI score compared to non-users $[13,14]$. The lower FSFI score has been proposed as one of the possible factors for our Malaysian women refuses to practice or discontinue their contraception [15].

Despite that, there is lack of study available for the prevalence of FSD among contraceptive users in Malaysia. The possible cause could be Malaysia is a multicultural community and the issue on FSD is not widely discussed, as sexuality remains a taboo among our community regardless of ethnicities. The results of this study may give the idea to clinician and researcher the prevalence and the main problem of sexual dysfunction in women practising contraception.

\section{Methods}

A cross-sectional study was conducted at eleven government health clinics under Seremban district in Negeri Sembilan, Malaysia from 2014 to 2016, whose locations were in urban and rural areas. This site was chosen mainly because of Seremban is the biggest district in Negeri Sembilan, Malaysia and also a logistic reason. All the eleven clinics provide a subsidized family planning service to all Malaysia citizen under women's health program. The study subjects were women, age more than 18 years old who are practicing contraception and attended family planning clinic in health clinics of Seremban district during the study period. The inclusion criteria were women who practiced contraception for the at least 1-month duration, sexually active with partner either caressing, foreplay, masturbation or vaginal intercourse for the past 1 month, understand Malay and consented for the study. Women who are illiterate were excluded from the study.

Sample size estimation for this study was calculated based on 2 sample proportion formula [16]. By taking the power of study $90 \%$ and significance level $\alpha$ at 0.05 with $95 \%$ confidence interval, the sample size estimation was 262. Subjects of 262 were selected using systematic random sampling at an interval of 10. The patients were given the questionnaire including the clear definition of terms and instructions for self-completion with inform consent. The basic socio-demographic data of the subjects included age, race, educational status, duration of the marriage, partner's age, any dissatisfaction of marital relationship, the frequency of sexual intercourse, menstrual pattern, types of contraception including duration on contraception use, any underlying medical illness, and smoking habit.

The sexual dysfunction was assessed with a validated Malay version of the female sexual dysfunction index (MVFSFI). MVFSFI is a translated version of Female Sexual Function Index to assess the sexual function in women for the past 4 weeks. FSFI was first proposed by Rosen [7] in 2000 and validated in Malay version by Sidi [8] in 2007 for usage among our local population. It consists of 19 questions on sexual function pertaining to 6 different sexual domains that are desire, arousal, lubrication, orgasmic, dissatisfaction and pain. The questionnaire assessed participant's sexual function during the last four weeks.

Sexual desire was assessed as frequency and desire level with two questions. Arousal was assessed as frequency, level of arousal, and confidence and arousal satisfaction with four questions. Lubrication was assessed as frequency, difficulty, frequency of maintaining and difficulty in maintaining with four questions. Orgasm was assessed as frequency, difficulty and satisfaction with three questions. Satisfaction was assessed as the amount of intimacy with partner, sexual relationship and overall sexual life with three questions. Pain was assessed as frequency during and after sexual activity and level of pain with three questions.

Each question in the questionnaire has five to six options for the patient to choose the most likely answer representing their sexual function within four weeks prior to the time of answering the questionnaire. The score for each answer is given from 0 to 5. A lower score indicates the higher probability of having sexual dysfunction. However, the score is only for researcher references. It is not revealed in the questionnaires to prevent the patient from trying to score their sexual function rather than giving an honest answer. The scoring for each question was from 0 (lowest) until 5 (highest) and the lower the score indicates the higher chance of having FSD.

The data were analyzed using SPSS version 23 . The prevalence of female sexual dysfunction and the percentage of each domain was calculated. A total score of 55 was taken as the cutoff point for the MVFSFI to differentiate between women with and without sexual dysfunction with a sensitivity of $98.8 \%$ and specificity of $98.5 \%$. The cut-off point for each domain was summarized in table $1 ; \leq 5$ for sexual desire disorder, $\leq 9$ for sexual arousal disorder, $\leq 10$ for lubrication disorder, $\leq 4$ for the orgasmic disorder, $\leq 11$ for sexual dissatisfaction disorder and sexual pain disorder a cutoff point of $\leq 7$ [8]. 
Table 1. MVFSFI scoring for each domain

\begin{tabular}{llllll}
\hline $\begin{array}{l}\text { Sexual Function Item number Score range } \\
\text { Domain }\end{array}$ & $\begin{array}{l}\text { Minimum } \\
\text { Score }\end{array}$ & $\begin{array}{l}\text { Maximum } \\
\text { score }\end{array}$ & Cut off point \\
\hline Desire & 1,2 & $1-5$ & 2 & 10 & 5 \\
Arousal & $3,4,5,6$ & $0-5$ & 0 & 20 & 9 \\
Lubrication & $7,8,9,10$ & $0-5$ & 0 & 20 & 10 \\
Orgasm & 11,12 & $0-5$ & 0 & 10 & 4 \\
Satisfaction & $13,14,15,16$ & $0 / 1-5^{\star}$ & 2 & 20 & 11 \\
Pain & $17,18,19$ & $0-5$ & 0 & 19 & 7 \\
Total & $1-19$ & & 4 & 95 & 55 \\
\hline
\end{tabular}

Ethical approval from the Ethics Committee of Universiti Putra Malaysia and National Medical Research Registry (NMRR-16-382-29228), Ministry of Health, Malaysia was obtained prior to the study. Permission from Health Department of Negeri Sembilan, Malaysia was also done as this study was carried out in their vicinity. Written informed consent was obtained from all participants before they take part in the study.

\section{Results}

A total of 262 women were recruited in this study. Demographic characteristics of the participants are shown in Table 2. The prevalence of female sexual dysfunction based on the MVFSFI questionnaire among contraceptive user in this study was $9.5 \%$ (Figure 1). The mean age of the women practicing contraception was 32 years in both FSD and nonFSD group.

Table 2. Characteristics of the subjects $(n=262)$

\begin{tabular}{|c|c|c|}
\hline Variables & $\begin{array}{c}\text { No FSD } \\
N=237(\%)\end{array}$ & $\begin{array}{c}\text { FSD } \\
\mathrm{N}=25(\%)\end{array}$ \\
\hline Age $($ Mean $\pm S D)$ & $31.96 \pm 6.08$ & $31.8 \pm 6.4$ \\
\hline \multicolumn{3}{|l|}{ Ethnicity } \\
\hline Malay & $202(92.2)$ & $17(7.8)$ \\
\hline Chinese & $11(78.6)$ & $3(21.4)$ \\
\hline Indian & $10(66.7)$ & $5(33.3)$ \\
\hline Others & $14(100)$ & $0(0)$ \\
\hline \multicolumn{3}{|l|}{ Educational level } \\
\hline Tertiary & $62(93.9)$ & $4(6.1)$ \\
\hline Secondary & $166(88.8)$ & $21(11.2)$ \\
\hline Primary & $9(100)$ & $0(0)$ \\
\hline \multicolumn{3}{|l|}{ Occupational status } \\
\hline Employed & $123(92.5)$ & $10(7.5)$ \\
\hline Non-employed & $114(88.4)$ & $15(11.6)$ \\
\hline \multicolumn{3}{|l|}{ Menstrual pattern } \\
\hline Regular & $131(91)$ & $13(9)$ \\
\hline Irregular & $106(89.8)$ & $12(10.2)$ \\
\hline \multicolumn{3}{|l|}{$\begin{array}{l}\text { Presence of medical } \\
\text { illness }\end{array}$} \\
\hline No & $208(91.2)$ & $20(8.8)$ \\
\hline Yes & $29(85.3)$ & $5(14.7)$ \\
\hline \multicolumn{3}{|c|}{ Taking other types of medication } \\
\hline No & $213(91)$ & $21(9)$ \\
\hline Yes & $24(85.7)$ & $4(14.3)$ \\
\hline \multicolumn{3}{|l|}{ Duration of marriage } \\
\hline Mean + SD & $8.2+5.69$ & $8.48+5.62$ \\
\hline \multicolumn{3}{|l|}{ Age spouse } \\
\hline Mean + SD & $35.3+7.5$ & $34.4+6.81$ \\
\hline \multicolumn{3}{|l|}{ Number of kids } \\
\hline Mean + SD & $2.61+1.33$ & $2.68+1.31$ \\
\hline Frequency of sexua & & \\
\hline
\end{tabular}

$\begin{array}{lll}\text { Mean + SD } & 6.52+4.01 & 5.56+3.43\end{array}$

Dissatisfy with marital relationship

$\begin{array}{lcc}\text { No } & 228(91.9) & 20(8.1) \\ \text { Yes } & 9(64.3) & 5(35.7)\end{array}$

Values are numbers (percentages)

$\mathrm{FSD}=$ Female Sexual Dysfunction

$\mathrm{SD}=$ Standard deviation

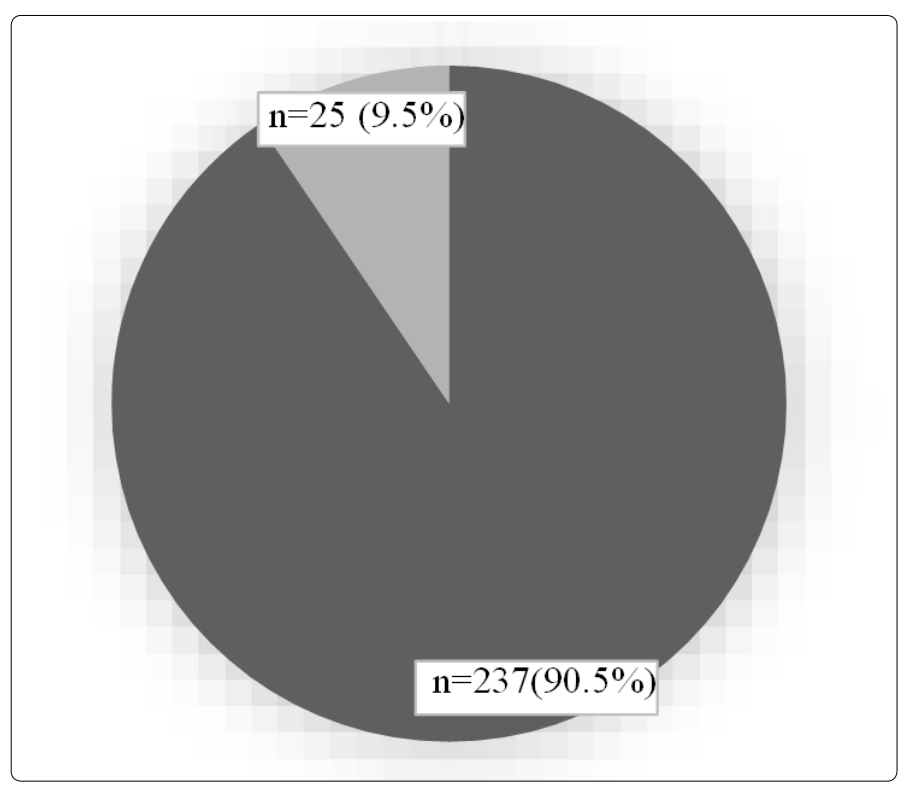

Figure 1. Prevalence of FSD

Of the total 25 participants with FSD, Indian and Chinese ethnic group were more prevalent of FSD compare to Malay ethnicity $(33.3 \%$ and $21.4 \%$, respectively). Majority of participants in FSD group have a secondary educational level (11.2\%) and non-employed (11.6\%). The mean duration of marriage for both groups was 8.5 years and the FSD group have less frequency of sexual intercourse compared to nonFSD group (5.6 and 6.5 times per month respectively). Majority of the participant (35.7\%) in FSD group were dissatisfied with their marital relationship.

The most common method of contraception used among FSD group was hormonal contraception (17.7\%) and most of them have been used contraception less than six months' duration as shown in Table 3.

Table 3. Types and duration of contraception $(n=262)$

\begin{tabular}{lcc}
\hline Variables & No FSD & FSD \\
& $\mathrm{N}=237(\%)$ & $\mathrm{N}=25(\%)$ \\
\hline Types of contraception & $36(92.3)$ & $3(7.7)$ \\
$\quad$ Non - hormonal & $201(90.1)$ & $22(9.9)$ \\
$\quad$ Hormonal & & \\
Duration of contraception & $57(85.1)$ & $10(14.9)$ \\
$\quad<6$ months & $180(92.3)$ & $15(7.7)$ \\
$\quad \geq 6$ months &
\end{tabular}

Values are numbers (percentages)

$\mathrm{FSD}=$ Female Sexual Dysfunction

$\mathrm{SD}=$ Standard deviation

Based on MVFSFI score (Table 4), sexual dissatisfaction and sexual desire disorder were among the most affected FSD domain among women practising contraception which was $29.8 \%$ and $29.4 \%$ respectively. Only $0.8 \%$ of the participant in this study had an orgasmic disorder 
Table 4. Types of female sexual dysfunction among contraceptive user base on Malay version of the Female Sexual Function Index

\begin{tabular}{ll}
\hline & $\mathrm{n}(\%)$ \\
\hline Sexual desire disorder & $77(29.4)$ \\
Sexual arousal disorder & $24(9.2)$ \\
Sexual pain disorder & $21(8)$ \\
Sexual dissatisfaction & $78(29.8)$ \\
Disorder of lubrication & $13(5)$ \\
Orgasmic disorder & $2(0.8)$ \\
\hline
\end{tabular}

\section{Discussion}

Based on our study, the prevalence of FSD among women practicing contraception was $9.5 \%$, which is lower compared to the study conducted among women less than 35 years old who are also practising contraception [13]. The differences between the studied population and the cut- off points of FSFI score in both studies could be the reason of different in the reported prevalence. Based from MVFSFI, the cut-off score of having a risk of FSD was $\leq 55$, while the cut-off score used in women less than 35 years old was $\leq 27$ [13]. The cut-off score for MVFSFI was based on the sensitivity and specificity of the score around the midpoint between the minimum and maximum scores as seen in the receiver operating characteristic (ROC) curve [4]. Meanwhile, the FSFI cut-off score was determined by using other statistical method that was CART analysis [17]. Our reported prevalence is also lower compared to Malaysian women in general population [4, 9]. The possible reasons could be due to different in inclusion and exclusion criteria. Our study only recruited women who are practising contraception while Sidi et al and Ishak et al included menopausal women as their studied population. As we know, menopause is one of the factors associated with FSD [18]. Therefore, excluding menopausal women may significantly affect the proportion of FSD in our studied population.

The various type of contraception used by the participant also will affect the result of the prevalence of FSD. A study done by Echeverry et al found that the prevalence of FSD was higher (29\%) among women practicing contraception compare to our study [19]. The reason behind that was they include women who used a natural method of contraception either coitus interrupts or calendar method, while our study includes women who were on modern contraceptive method only.

Malaysia is a well-known country of a multi-racial and a multi-cultural population. However, there is no available data to compare the prevalence of sexual dysfunction among a different ethnic group in Malaysia. This study revealed that most of the women with FSD were Indian and Chinese ethnicity which was $33.3 \%$ and $21.4 \%$ respectively. This study also found that hormonal contraception was the common method used among women with FSD (9.9\%).

Stability of the relationship was reported to be one of the factors that may contribute to FSD [20]. It was reported that women in an unstable relationship had higher FSD $[13,21]$. A study conducted in Tehran among middle-aged men and women reported that marital satisfaction was strongly associated with sexual satisfaction [21]. Our study also revealed that majority of women with FSD was dissatisfied with their marital relationship (36\%). In addition, women especially Malays are not allowed to disclose any problem in sexual relationship with their partners due to cultural and religious belief [22]. Therefore, the increase in reported sexual dissatisfaction among our studied participants should be regarded as a genuine feedback.

The commonest reported type of sexual dysfunction in general population in Malaysia was sexual desire disorder which comprises of $39.3 \%$, followed by arousal disorder $25.8 \%$ [9]. This study found that sexual dissatisfaction and sexual desire were the highest reported of sexual dysfunction domain which was $29.8 \%$ and $29.4 \%$ respectively among contraceptive user. The differences between the studied populations likely contribute to the differences in the reported types of sexual dysfunction. Our finding also inconsistent with findings by Wallwiener et. al whereby they reported the highest affected sexual domain among younger age group who practising contraception was the orgasmic problem [13]. However, these two studies cannot be compared as many factors may influence the sexual function index of the studied population. Besides that, the presence of psychological or emotional disturbances, relationship stress, and partner's sexual dysfunction were the other reason of sexual dysfunction in women [23].

This study has few limitations. Firstly, the self-reported questionnaire of MVFSFI may not reflex the true problems. Participants may choose the answer which is not truly happened in their sexual life. Secondly, recall bias may also occur because they only can report on their last four weeks' sexual activity.

\section{Conclusion}

This study provides the preliminary data on the prevalence of sexual dysfunction among contraceptive user in Malaysia. The results show that the prevalence of sexual dysfunction is low in women practising contraception. The high percentage of sexual dissatisfaction and desire disorder in women practicing contraception suggests that hormonal contraception may have an effect on sexual function. Primary care provider should counsel women before offering them with contraception.

\section{Acknowledgements}

We would like to acknowledge the Director General of Health Malaysia for his support and approval to publish this paper. We would like to express our thanks to Health Department of Negeri Sembilan, Malaysia for giving permission to conduct the study in the Seremban district health clinic. Special thanks to Prof. Dr. Hatta Sidi for allowing us to use MVFSFI.

\section{Conflicts of Interest}

The author has no conflicts of interest to declare. 


\section{References}

1. Kingsburg SA, Iglesia CB, Kellogg S, Krychman ML. Handbook of female sexual health and wellness; 2011.

2. Christensen BS, Grønbæk M, Osler M, et al. Sexual dysfunctions and difficulties in denmark: prevalence and associated sociodemographic factors. Arch Sex Behav. 2011; 40(1): 121-132. doi: 10.1007/s10508-0109599-y

3. Valadares $\mathrm{AL}$, Pinto-Neto $\mathrm{AM}$, Osis MJ, et al. Prevalence of sexual dysfunction and its associated factors in women aged 40-65 years with 11 years or more of formal education: a population-based household survey. Clinics (Sao Paulo). 2008; 63(6): 775-782.

4. Sidi H, Puteh SE, Abdullah N, Midin M. EPIDEMIOLOGY: The Prevalence of Sexual Dysfunction and Potential Risk Factors That May Impair Sexual Function in Malaysian Women. J Sex Med. 2007; 4(2): 311-321. doi: 10.1111/j.1743-6109.2006.00319.x

5. Grewal GS, Gill JS, Sidi H, et al. Prevalence and risk factors of female sexual dysfunction among healthcare personnel in Malaysia. Compr psychiatry. 2014; 55 (Suppl 1): S17-S22. doi: 10.1016/j.comppsych.2013.01.009.

6. Basson R, Berman J, Burnett $A$, et al. Report of the international consensus development conference on female sexual dysfunction: definitions and classifications. J Urol. 2000; 163(3): 888-893. doi: 10.1016/S00225347(05)67828-7

7. Rosen R, Brown C, Heiman J, et al. The Female Sexual Function Index (FSFI): a multidimensional self-report instrument for the assessment of female sexual function. J Sex Marital Ther. 2000; 26(2): 191-208. doi: 10.1080/009262300278597

8. Sidi H, Abdullah N, Puteh SE, Midin M. The Female Sexual Function Index (FSFI): Validation of the Malay version. J Sex Med. 2007; 4(6): 1642-1654. doi: 10.1111/j.1743-6109.2007.00476.x

9. Ishak IH, Low WY, Othman S. Prevalence, risk factors, and predictors of female sexual dysfunction in a primary care setting: a survey finding. J Sex Med. 2010; 7(9): 3080-3087. doi: 10.1111/j.1743-6109.2010.01848.x

10. Burrows $\sqcup$, Basha $M$, Goldstein AT. The effects of hormonal contraceptives on female sexuality: a review. J Sexual Med. 2012; 9(9):2213-2223. doi: 10.1111/j.1743-6109.2012.02848.x

11. Strufaldi R, Pompei LM, Steiner ML, Cunha EP, Ferreira JA, Peixoto S, et al. Effects of two combined hormonal contraceptives with the same composition and different doses on female sexual function and plasma androgen levels. Contraception. 2010; 82(2): 147-154. doi: 10.1016/j. contraception.2010.02.016
12. Greenstein $A$, Ben-Aroya $Z$, Fass $O$, et al. Vulvar vestibulitis syndrome and estrogen dose of oral contraceptive pills. J Sex Med. 2007; 4(6): 1679-1683. doi: 10.1111/j.1743-6109.2007.00621.x

13. Wallwiener CW, Wallwiener $L M$, Seeger $H$, Mück AO, Bitzer J, Wallwiener $M$. Prevalence of sexual dysfunction and impact of contraception in female German medical students. J Sex Med. 2010; 7(6): 2139-2148. doi: 10.1111/j.1743-6109.2010.01742.x

14. Fataneh $G$, Marjan MH, Nasrin $R$, Taraneh $T$. Sexual function in Iranian women using different methods of contraception. J Clin Nurs. 2013; 22(21-22): 3016-3023. doi: 10.1111/jocn.12289

15. Najimudeen $\mathrm{M}$, Sachchithanantham K. An insight into low contraceptive prevalence in Malaysia and its probable consequences. Int J Reprod Contracept Obstet Gynecol. 2014; 3(3):493-496. doi: 10.5455/2320-1770. ijrcog20140943

16. Lwanga SK, Lemeshow S. World Health Organization. Sample size determination in health studies: a practical manual; 1991.

17. Wiegel $M$, Meston $C$, Rose $R$. The female sexual function index (FSFI): cross- validation and development of clinical cutoff scores. J Sex Marital Ther. 2005; 31(1): 1-20. doi: 10.1080/00926230590475206

18. Verit FF, Verit A, Billurcu N. Low sexual function and its associated risk factors in pre- and postmenopausal women without clinically significant depression. Maturitas. 2009; 64(1): 38-42. doi: 10.1016/j.maturitas.2009.07.002

19. Echeverry MC, Arango A, Castro B, Raigosa G. Study of the prevalence of female sexual dysfunction in sexually active women 18 to 40 years of age in Medellín, Colombia.JSexMed.2010; 7(8):2663-2669. doi:10.1111/j.1743-6109.2009.01695.x

20. McCabe MP, Connaughton C. Sexual dysfunction and relationship stress: how does this association vary for men and women? Current Opinion in Psychology. 2017; 13: 81-84. doi:10.1016/j.copsyc.2016.05.007

21. Rahmani A, Khoei EM, Gholi LA. Sexual Satisfaction and its Relation to Marital Happiness in Iranians. Iranian J Publ Health. 2009; 38(4): 77-82.

22. Pastor Z, Holla K, Chmel R. The influence of combined oral contraceptives on female sexual desire: a systematic review. Eur J Contracept Reprod Health Care. 2013; 18(1): 27-43. doi: 10.3109/13625187.2012.728643

23. Wallwiener $\mathrm{CW}$, Wallwiener $\mathrm{LM}$, Seeger $\mathrm{H}$ et al. Are hormonal components of oral contraceptives associated with impaired female sexual function? A questionnaire-based online survey of medical students in Germany, Austria, and Switzerland. Arch Gynecol Obstet. 2015; 292(4): 883-890. doi: 10.1007/s00404-015-3726-x 